\title{
Revista Dramática: São Paulo, 1860. São Paulo, EDUSP, 2007. Prefácio de Jacó Guinsburg e Rosangela Patriota
}

\author{
Elizabeth R. Azevedo
}

importante para os estudos teatrais que a EDUSP tenha incluído a Revista Dramática na série de reproduções facsimilares que começa a publicar, e que pretende abarcar outros jornais paulistanos, além de peças teatrais, sermões e orações, todos produzidos no século XIX em São Paulo. Desse modo, põe-se à disposição dos estudiosos e do público interessado um acervo que, até agora, permanecia pouco acessível, fechado nas coleçôes de raridades das bibliotecas paulistas.

A Revista Dramática é, com pouquíssimos outros documentos referentes ao teatro na capital paulista no século XIX, ${ }^{1}$ o testemunho do empenho de alguns apaixonados idealistas e a tentativa de tornar São Paulo e os estudantes do Largo de São Francisco um pólo da reflexão sobre a arte teatral.

A publicação nos remete à época de criação dos Cursos Jurídicos, em 1827, e a instala- ção da Faculdade de Direito em São Paulo no velho convento dos franciscanos no ano seguinte, que marcou o início de uma nova etapa na história da cidade. O empenho dos estudantes em discutir os caminhos futuros da nova nação, recentemente independente, fez surgir uma série inédita de publicaçōes, associaçōes, clubes e irmandades. O fenômeno, que perdurou pelas décadas seguintes, não deixou de apresentar iniciativas relativas às artes em geral e ao teatro em particular.

Em 1860, Pessanha Póvoa editou a Revista Dramatica, lançando vinte e dois números agrupados em cinco cadernos, entre maio e setembro. Essa foi uma das raríssimas publicaçōes paulistanas no século XIX dedicada exclusivamente ao teatro. ${ }^{2}$

José Joaquim Pessanha Póvoa era estudante no Largo de São Francisco, vindo do Rio de Janeiro onde tinha nascido em São João da Barra, em 1836. Anos mais tarde, atuou como

Elizabeth R. Azevedo é professora do Departamento de Artes Cênicas e do Programa de Pós-Graduação em Artes Cências da ECA-USP.

1 Ensaios sobre a tragédia, de F. Bernardino Ribeiro, Justiniano José da Rocha e A. A. Queiroga, de 1833; Carta sobre a atualidade do teatro entre nós, e Puff- Prefácio a Macário, de Álvares de Azevedo, 1851 (datas prováveis); Carta ao ator Joaquim Augusto Ribeiro de Souza, de Castro Alves, em 1868, e Ensaios dramáticos, de Diogo de Mendonça Pinto, de 1872.

2 Pode-se ainda citar: Echos Theatrais (Vida Paulista), de 1895, com 6 números; O Entre-Acto, de 1898, com um único número e $A$ Arte, também com um só número publicado no segundo semestre de 1900. 
chefe de polícia na corte, político e parlamentar no Espírito Santo. Esses dados, que poderiam parecer apenas curiosidade biográfica, adquirem relevância se comparados às declaraçôes feitas pelo autor no primeiro editorial da Revista, publicado em 6 de maio de 1860:

(...) A publicação que empreendemos tem por fim despertar as vocaçōes dramáticas que desvairadas abraçam mil seduções da política, abutre insaciável, que só consente liberdade e vida àqueles que por ele se apaixonam. (...) Nossa pátria, muito tarde, virá a convencerse de que os grandes homens só apareceram nos séculos literários, que contribuíram mais para a civilização dos impérios: que a literatura é fonte de instrução, de felicidade, é caminho certo para a conquista da glória, é o éculo das inspirações enérgicas, é quem prepara a independência dos povos, é quem esclarece os horizontes impregnados de miasmas políticos dos governos monopolizadores. ${ }^{3}$

E em um número posterior

No estado atual das coisas dois elementos podem salvar nossa pátria da apatia em que vegeta, da futura vergonha que virá cortejála: é a literatura e a revolução. (...) Basta de política exclusivamente porque ela só deifica as divindades da época, só respeita o manto de Pluto, só obedece à manopla de Midas, só condescende com as imposições da raça e posição dos duques de Medina Celi. Só prepara o veículo para os grandes, e segrega os direitos dos pequenos quando estes são ignorantes. Para nós ela é inútil porque aquela. ${ }^{4}$
Esse foi sempre o tom dos cinco editoriais publicados pela Revista Dramatica, quatro deles assinados por Póvoa. A tese ardentemente defendida era de que a arte (e o teatro em especial) deveria se desenvolver para iluminar os espíritos, formando-os no exercício da nacionalidade, da soberania e da cidadania. No entanto, Póvoa seguiu o destino da maioria dos egressos da faculdade daquela época - envolveu-se com a política e a administração pública. De certa forma, ele tinha razão em temer a atração que ambas exerciam sobre a intelectualidade brasileira. ${ }^{5}$

A Revista Dramatica visava claramente o grupo acadêmico e pretendia inspirá-lo a exercer o nobre ofício da arte teatral. Para tanto, Póvoa idealizou uma publicação que compreendia o teatro em seus diversos aspectos e não só na sua dimensão literária. Por isso mesmo, trazia matérias sobre a história do teatro, críticas dos espetáculos apresentados na cidade (com apreciaçóes sobre o desempenho dos atores e atrizes), transcrevia artigos sobre os movimentos teatrais fora de São Paulo, apresentava notícias sobre música, discutia questôes técnicas, a relação do palco com a censura, as traduções e os empresários. Os artigos estão agrupados ao longo dos diversos números de uma maneira um tanto caótica, sem seções bem definidas, com subdivisões pouco claras. Às vezes, são apresentados na íntegra, em um único número, em outras, são divididos em vários trechos publicados ao longo das semanas. Pessanha Póvoa responsabilizou-se pelo maior número de artigos assinados (os editoriais, "Theatro" em 4 partes, "Músicos acadêmicos" em 6, "João Soares", ${ }^{6}$ em 3) e provavelmente por outros anônimos.

3 Pessanha Póvoa - Revista Dramática, n. ${ }^{\circ} 1,6$ de maio de 1860, p.1.

4 Pessanha Póvoa - Revista Dramática, n. ${ }^{\circ} 6,10$ de junho de 1860, p.22.

5 Para o teatro, Póvoa escreveu ainda Os dois mundos: academia-teatro, em 1861; Literatura do palco (artigos para o Jornal do Comércio) e Anos acadêmicos (onde faz diversas referências ao teatro paulistano entre 1861 e 64$)$.

6 Engenheiro e teatrólogo paulistano. 
Para auxiliá-lo, Póvoa arregimentou alguns outros alunos que comungavam de seus ideais, como Salvador de Mendonça, também vindo do Rio, em 1859, onde convivera com Machado de Assis, Joaquim Manuel de Macedo, Casemiro de Abreu, Gonçalves de Magalhães e Araújo Porto-Alegre, e que se tornaria um republicano histórico e fundador da Academia Brasileira de Letras. É dele, sob o pseudônimo de Tacitus, o maior número de artigos assinados, depois do próprio Pessanha Póvoa. Mendonça encarregou - se de matérias sobre o teatro na corte, atacando a má influência de João Caetano enquanto empresário sobre o desenvolvimento da dramaturgia nacional, e como ator por agarrar-se à antiga escola dos melodramas e tragédias neoclássicas que o tinham consagrado. A seguir, analisou o novo estilo que vinha se firmando na corte - o Realismo -, centrado no Teatro do Ginásio Dramático e no trabalho do ator Furtado Coelho, embora deplorasse também a atuação do empresário do grupo, Joaquim Heliodoro Gomes.

A discussão em torno da nova e da velha escola se repete em outras matérias, assinadas ou não. Uma curiosidade é a posição, um tanto confusa, defendida por Fagundes Varela 7 (aluno do primeiro ano) que ataca Shakespeare, Racine, Molière, entre outros, defendendo o exemplo de Scribe, Musset e dos Dumas (pai e filho).

Sobre a arte do ator, a revista deu voz a João Caetano, através da reprodução de trechos de seu livro Reflexôes Dramáticas (de 1837), apesar de defender um estilo mais moderno de re- presentação. ${ }^{8}$ As considerações sobre o trabalho dos artistas da única companhia existente em São Paulo nessa época vão nessa direção, procurando corrigir os exageros e sublinhando a necessidade de adequação ao personagem e da expressão sincera e natural dos sentimentos.

A revista, contudo, teve fôlego curto, findou-se, como o próprio editor declarou na penúltima nota da revista, por falta de colaboradores:

Até hoje tenho publicado vinte e dois números, e nesses, dos colaboradores que tive, os quais só se entusiasmaram com a idéia, mas não me auxiliaram no trabalho, publiquei alguns artigos, que numero seis. Só, tenho sustentado na parte literária; só, tenho tido o prejuízo na publicação. ${ }^{9}$

No entanto, Póvoa era um otimista incorrigível e na nota seguinte, a última, noticia a "auspiciosa" criação de uma Sociedade Dramática, também calcada basicamente na atuação dos acadêmicos. Quem sabe essa daria certo...

Impulso à literatura dramática. - Funda-se por estes dias uma sociedade dramática, a qual conta com cinqüenta estudantes do curso jurídico e algumas pessoas desta capital, que pretendem no mês de março apresentar composições nacionais, especialmente dramas, com assuntos exclusivamente nossos. Foi convidado o distinto literato Ernesto Ferreira França - para Presidente. ${ }^{10}$

7 Varela, F. O drama moderno. Revista Dramática, no 4, 27 de maio de 1860, p.14-5.

8 Retomando uma discussão anedótica sobre bigodes que havia envolvido Furtado Coelho - Revista Dramática, n. ${ }^{\circ} 2,13$ de maio de 1860, p.6.

9 Pessanha Póvoa - Revista Dramática, n.ํ22, 14 de outubro de 1860, p.88.

10 O Instituto foi realmente criado e além de Ferreira França participaram Sizenando Nabuco e Rodrigo Otávio de Oliveira Menezes. Chegou a organizar leituras públicas de obras inéditas como Otávio, de Sizenando, Jorge, de Rodrigo Otávio e Sangue Limpo e Traficantes de escravos, de Paulo Eiró. É o próprio Póvoa (em Anos Acadêmicos) que dá notícia do fim das atividades do Instituto por falta de participantes, como ocorrera com a Revista Dramatica. 
Na verdade, a Revista Dramatica representou um esforço ambicioso e memorável de se manter uma publicação tão especializada sem condições comerciais de sustentação necessárias, graças ao idealismo de seu editor e à importância que ele atribuía ao teatro. 